\section{A philosopher's point of view}

SIR - I should like to comment, from a philosophical rather than a scientific point of view, on John Godfrey's Commentary ${ }^{1}$ and the correspondence that has followed it.

A recurrent problem in discussing these questions comes from the relationship between the terms 'person' and 'human being'. An individual who is entitled to certain kinds of protection, such as not being killed or experimented on without consent, can be said to have the status of a person. Creatures who have this status also, typically, have certain characteristics such as capacities for language use, reason, taking part in what are indeed called personal relations and so on. But a given individual does not have actually to display all, or perhaps any, of those characteristics in order to enjoy the status. If that were so, infants and the mentally incapable would enjoy no protection. Nor can one say that any individual who enjoys the status must have the potentiality for developing the characteristics: that excludes the irreversibly mentally incapable. Rather, you have to say that the status belongs to the kind of individual that typically displays the characteristics; and that, in terrestrial experience at least, is a human being.

So, in discussing origins, we can leave the term 'person' out of it - not because it has nothing to do with the moral argument, but because it represents the conclusion of the argument (protection should be given) and not the basis of that conclusion. The question must be entirely about the development of a human being, and in particular whether the zygote is a human being. One of your Roman Catholic correspondents ${ }^{2}$ wrote that "as with any other animal species, fertilization is the moment when an individual human starts its development". This is in one sense indisputable: fertilization is the moment when something starts to develop into a human being. But this does not mean that it is the moment when an already existent human being starts doing something, namely developing. The reference to other species is well taken. By this argument, there would be no reason to deny that a caterpillar was a butterfly; but those who came to see butterflies, and put value on their beauty, would be reasonably disappointed if they saw only caterpillars.

The development of a human being is development into a human being, and it is indeed a gradual process. To prevent out-

\section{Correspondence}

Letters submitted for Correspondence should be typed, double-spaced, on one side of the paper only. rages such as experiment on neonates, we draw a line to govern these things, and we are wise to draw it early. But there is no reason in the metaphysics of persons or human beings that requires us to draw it at the very beginning.

\section{Bernard Williams}

Corpus Christi College,

Oxford, OXI 4JP, UK

SIR - The question of what counts as a human being is more complex than Benjamin Libet ${ }^{3}$ allows. The distinction he makes between "human life" and "the life of a human person" should be replaced by a threefold division.

Something is a mere bit of human life if it is both human and alive: a leukocyte, for example. A human embryo may not be a human being, but it is certainly a human entity in a stronger sense than this - as it is both human and alive and has a natural continuity with such as you or me. It is not at all surprising that some people will say that it is a human being - but no one would say such a thing about a blood corpuscle. But there are arguments against regarding a zygote as a human being ${ }^{4}$. And indeed it is somewhat unnatural to suppose so: one is inclined to take it for granted that every human being must have a head and a certain number of organs, and that no human being is spherical. If one could take a drug that would encourage uniovular twinning, no one would think it murder. A human bodily organization would seem to be necessary, like that established in the womb when an embryo turns into a fetus - an only roughly determinable time, needless to say, but a time noted by embryologists with no particular axe to grind. (The fact that the significant change is not instantaneous is of little importance.) An Aristotelian, for whom the soul was the "form" of the human being, might also take this view. A human being, one might say, has a ground plan. Of course some bits of the basic structure can be missing - one can be defective in various ways. But too many lacks destroy one's essence, so to speak. A car can lack a wheel, a seat, an engine, a bonnet. Take away too many such items and what is left is not a car, it is not even a defective one. In considering whether something is a human being we must not of course insist that the entity in question is fully developed, otherwise none of us would count until sexual maturity and the fusion of our long-bones. The word "person", where it does not mean "human being", or "man, woman or child", is nowadays best avoided: for some years now it has been defined by philosophers ad hoc, within a certain range, to suit their polemical purposes.

Further emphasis on the human brain would be questionable. In particular, it would be a mistake to consider whether the entity had present thoughts, for we do not suddenly cease to be human beings when we are knocked unconscious. In discussing these questions, it helps to realize that we are dealing with the identity of a mammal, and that our question could be asked in all its essentials about canine pregnancy and puppy dogs. And it helps too to forget, if only for a while, about the abortion issue. Early abortion could be wrong even if it were too early to count as murder. On the other hand, there are plenty of philosophers around who suppose it can be all right to kill born children, as indeed was thought in the Roman republic.

Christopher Coope

Department of Philosophy,

University of Leeds, Leeds LS2 9JT, UK

SIR - Libet ${ }^{3}$ presents a hypothesis on what we might call the biological markers associated with personhood. But Libet's assertions - that the central role of the brain is constant in determining personhood, and that postnatal brain death can be equated with neural activity in the embryo/fetus - appear to be based on questionable assumptions.

It is agreed that postnatal brain death denotes the end of the individual's life and personhood. What is not clear is the relevance of this to the start of a life or personhood. A human's life and personhood are linear processes of development, and as such the inception of the process need not resemble the end of the process. Indeed, for most linear processes, the starting and ending characteristics are not the same.

Also unclear is the substantive relevance of comparing neural activity in a normal embryo/fetus with brain death in a postnate. The former is an entirely normal state, providing all the neural activity required at that stage of human development. The latter represents a highly abnormal catastrophic loss of a requisite function. Further, a declaration of brain death requires that there should be no reasonable expectation of regaining brain activity. With the embryo/fetus there is every expectation that such activity will arise in a predictable time and manner.

History is filled with otherwise good people employing some set of characteristics (many based on 'real' science) to explain why another class of Homo sapiens is subhuman or otherwise undeserving of basic human rights. We study the lessons, and pride ourselves on condemning these episodes as acts of folly, arrogance and inhumanity. Yet in 1995, here we are again. Michael A. Zarowitz

981 Sunset Drive,

San Carlos, California 94070, USAO

1. Godfrey, J. Nature 373, 100 (1995).

2. Montuenga, L. M. Nature $\mathbf{3 7 4}, 10$ (1995)

3. Libet, B. Nature $\mathbf{3 7 5 , 1 0 0}$ (1995).

4. Anscombe, G. E. M. in Philosophy and Practice, (ed. A. Phillips Griffiths) (Cambridge University Press, 1985). 